\title{
Comparative morphology and allometry of select extant cryptodiran turtle kidneys
}

\author{
Christopher Thigpen ${ }^{1} \cdot$ Logan Best $^{2} \cdot$ Troy Camarata $^{2}$
}

Received: 21 May 2019 / Revised: 9 September 2019 / Accepted: 20 September 2019 / Published online: 28 September 2019

(c) The Author(s) 2019

\begin{abstract}
Reptile, avian, and mammalian species all possess a metanephric kidney to maintain fluid homeostasis. The physiology of the kidney is intimately related to tissue organization and gross morphology, which is dependent upon organ size, animal habitat, and body plan. Reptiles have significant variations in body plan and as a result have differences in visceral organ placement and morphology. One organ that appears to show great morphological variation is the reptilian kidney found in Crocodylia, Testudines, and Squamata (Sauria and Ophidia). However, limited research has been conducted to evaluate and compare kidney morphology in reptiles and more specifically, in turtles. Here we have examined multiple cryptodiran turtle species from the families Chelydridae, Emydidae, Kinosternidae, and Trionychidae. Detailed descriptions of kidney morphology along with comparative allometry are provided. Significant differences in external renal morphology were found between and within turtle families as well as differences in scaling of kidney mass with body mass. Our study provides a foundation for understanding differences in organ development and tissue architecture as well as potential differences in physiology.
\end{abstract}

Keywords Body mass $\cdot$ Kidneys $\cdot$ Preserved $\cdot$ Turtles $\cdot$ Allometry

\section{Introduction}

Amniotes share the ability to maintain water and ion homeostasis along with nitrogenous waste excretion via the metanephric kidney. Differences in renal function between mammals, avian reptiles, and non-avian reptiles are reflected in the variation of kidney morphology. The mammalian kidney ranges from the bean-shaped unipapillate kidney found in rodents to large multi-reniculated kidneys such as those found in whales (Dantzler and Braun 1980; Braun 1998). The retroperitoneal avian kidney consists of cranial, medial, and caudal lobes with the organ intimately recessed within the synsacral fossa (Johnson 1968; Dantzler and

Electronic supplementary material The online version of this article (https://doi.org/10.1007/s00435-019-00463-3) contains supplementary material, which is available to authorized users.

Troy Camarata

tcamarat@nyit.edu

1 Department of Biology, Arkansas State University, Jonesboro, AR 72467, USA

2 Department of Basic Sciences, NYIT College of Osteopathic Medicine at Arkansas State University, PO Box 119, Jonesboro, AR 72467, USA
Braun 1980). Five variations of the avian kidney have been described with a single morphological variant predominant in each family (Johnson 1968). The diversity in morphology and structure of the kidney is most likely due to different physiological demands, as nephron number (the functional unit of the kidney) does not scale with body mass at the same rate as metabolic rate or kidney mass in mammals (Braun et al. 2011).

In non-avian reptiles, significant variations in body plan are found among crocodiles, testudines, and squamates and this influences the gross morphology of the kidney. The bilaterally lobed kidneys of snakes and other ophidians have been described as long and narrow, rod-shaped organs (Braun 1998). Whereas the kidneys of tetrapod reptiles have been observed to be flat, elongated lobulated organs such as those found in lizards; or flat, compact ovals, as occurring in turtles (Fox 1977; Canny 1998). The turtle general gross morphology of the kidney has been described only for Testudo, Chelonia mydas (Linnaeus, 1758), Emys, and Chrysemys turtles (Fox 1977; Solomon 1985). A more detailed description of kidney gross anatomy as well as the renal portal system has been reported for Trachemys scripta elegans (Wied, 1839; Holtz et al. 1997; Silva et al. 2010). However, there is little detailed description of comparative 
renal morphology in turtles. Our previous work detailing the appearance of continual nephrogenesis in reptiles hinted at distinct variations in kidney morphology and tissue architecture (Camarata et al. 2016). The primary objective of this investigation is to describe, in detail, the comparative kidney morphology using imaging and allometry among select species of the turtle families Chelydridae, Emydidae, Kinosternidae, and Trionychidae.

\section{Materials and methods}

\section{Specimens}

Species used in this study included Chrysemys picta $(n=7)$, Trachemys scripta $(n=6)$, Pseudemys concinna $(n=6)$, Graptemys geographica $(n=5)$, Terrapene carolina $(n=4)$, Chelydra serpentina $(n=5)$, Macrochelys temminckii $(n=2$; only used for visual observations), Sternotherus odoratus $(n=7)$, Kinosternon subrubrum $(n=4)$, and Apalone spinifera $(n=13)$. All specimens were obtained from the Arkansas Center for Biodiversity Collections herpetology collection at Arkansas State University. Only turtles that were identifiable and fully intact were used for this study. Turtles accessed from the museum collection were measured and recorded for body mass, curved carapace length (CCL), and species. CCL measurements were taken as described for minimal curved carapace length (Bolton 1999). Next, the carapace was bilaterally separated from the plastron at the bridge and the plastron was removed. The caudal portion of the spinal column was separated from the carapace to allow removal of the caudal portion of the body from the carapace. Kidneys were photographed in situ once located and then excised for measurements. Kidney mass and the length of the kidneys along the craniocaudal axis were recorded. The mass and lengths of the left and right kidney were combined and averaged, which was then used for statistical comparisons. Excised kidney organs were stored in $70 \%$ ethanol and labeled with corresponding animal collection number.

\section{Statistical analysis}

All measurements were collected into a spreadsheet and imported into RStudio (Boston, MA). Data distribution was determined using a Shapiro-Wilk test. Kidney mass to body mass as well as kidney length to CCL correlation $P$ values were calculated using the Spearman rank correlation. Interspecies comparisons of body mass/kidney mass and CCL/ kidney length $P$ values were calculated using the Wilcoxon rank sum test. For linear regression, $\log$ (kidney mass) and $\log$ (body mass) of preserved specimens were used.

\section{Results}

\section{Diversity of kidney external morphology}

Chelydridae, Chelydra serpentina (Linnaeus, 1758) and Macrochelys temminckii (Troost, 1835), possessed kidneys that were intricate and intimately connected to the carapace (Fig. 1; M. temminckii not shown). In both chelydrid species, the kidneys were divided into lobes by the ribs with costal grooves visible in the dorsal portion of the organ where the kidney would cover and partially wrap around the ribs (Fig. 1, arrows). The kidneys rested medially along the vertebral column and ran parallel to the midline and had no apparent capsule (Fig. 1). The craniocaudal axis was approximately twice the length of the mediolateral axis. The kidneys angled slightly ventrally towards the caudal region.

Kidneys in the trionychid, Apalone spinifera (Lesueur, 1827), differ from all other families. The kidney position relative to the cranial-caudal axis in A. spinifera was oblique, rather than parallel, to the midline (Fig. 2). The kidneys were also visibly flattened, a characteristic much
Fig. 1 Images of adult kidney of Chelydra. a, b Dorsal view of Chelydra serpentina kidney in adult female (a) and male (b) with cranial axis toward top of image. Arrows in both $\mathbf{a}$ and $\mathbf{b}$ show renal costal grooves of the kidney. $L k$ left kidney, $R k$ right kidney. Scale bars $5 \mathrm{~mm}$
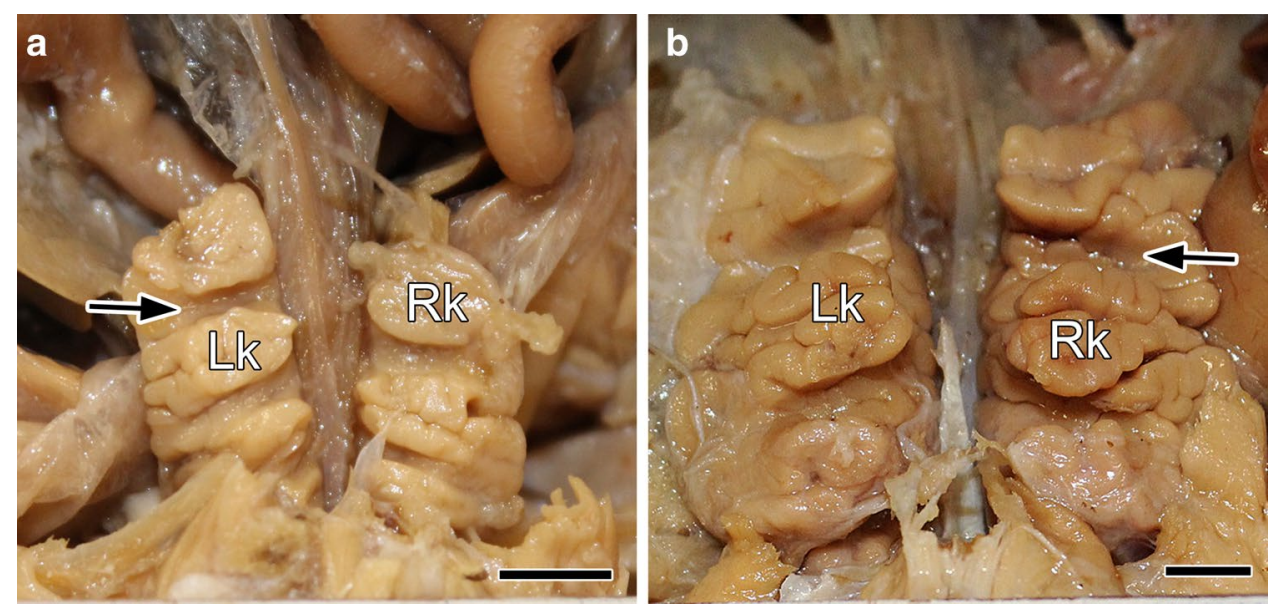

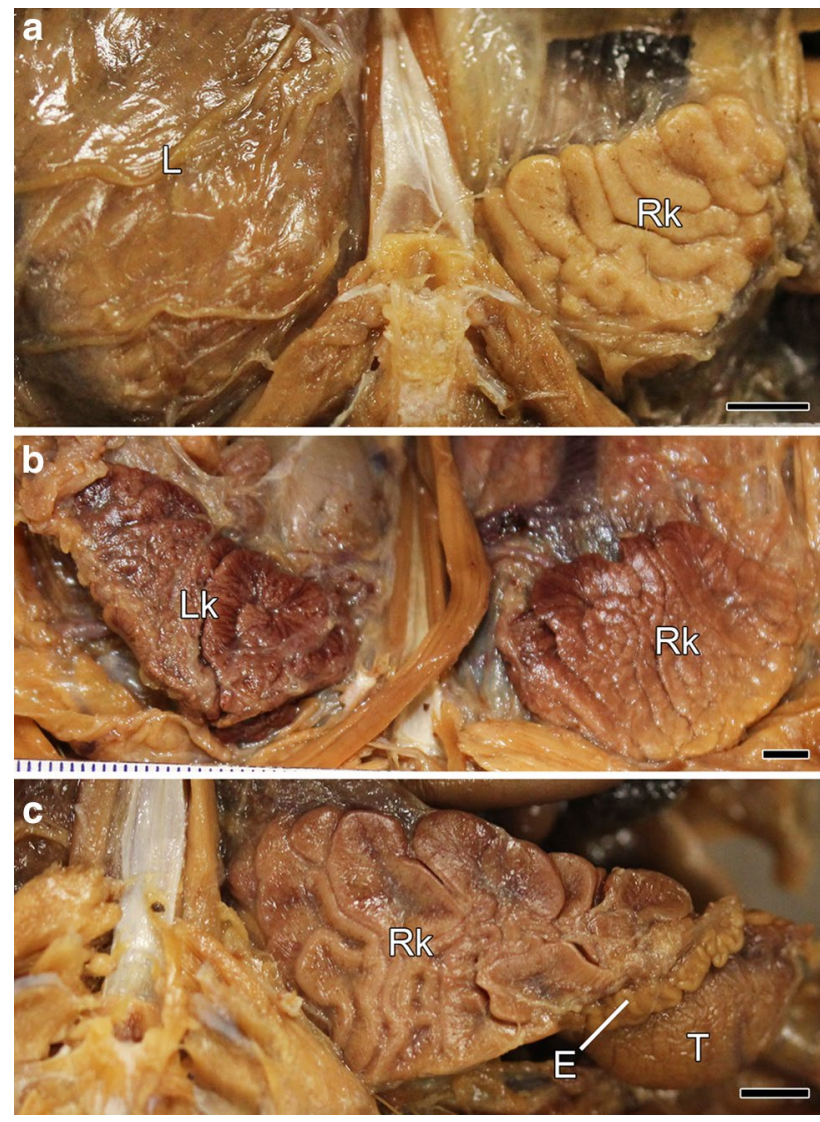

Fig. 2 Images of juvenile and adult kidney of Trionychidae. a Dorsal view of Apalone spinifera kidney in juvenile female. Right kidney is shown (Rk) with left kidney not visible under the lung (L). b, c Dorsal view of adult female and male (b and $\mathbf{c}$, respectively) kidney. In c, close association with epididymis (E, designated by line) and testes $(\mathrm{T})$ is observed with right kidney. Cranial axis toward top in all images. $L k$ left kidney, $R k$ right kidney. Scale bars $5 \mathrm{~mm}$

more evident in adult females. The kidneys were more square-shaped than those found in either chelydrid, having length-to-width ratios from 1:1 up to 1.4:1. The kidneys were parallel to the midline with each cranial and caudal pole even with the contralateral kidney. No craniocaudal or mediolateral angling of the kidneys were apparent.

The kinosternids, Sternotherus odoratus (Latreille, 1801) and Kinosternon subrubrum (Bonnaterre, 1789), possessed a capsule on the kidney, superficial to the convolutions and deep to the fascia (Fig. 3). The kidneys of both species lie parallel to the midline. The female kidneys of both species appeared to be laterally compressed, whereas male kidneys possessed a dorsal flange that extended laterally from the midline and is dorsoventrally compressed (compare Fig. 3a, c to b, d). The female kidneys had a length-to-width ratio of approximately 4:1 in $S$. odoratus and 3:1 in K. subrubrum. Male kidney ratios were 2.2:1 in both species. The kidneys had a slight ventral angle towards the caudal region.
Kidneys in the emydids, Chrysemys picta dorsalis (Schneider, 1783), Trachemys scripta elegans, Pseudemys concinna concinna (LeConte, 1830), and Terrapene carolina triunguis (Agassiz, 1857), all possessed distinct convolutions on the surface of the organ (Fig. 4). All females in the family appeared to have slightly wider kidneys that were relatively dorsoventrally compressed. Female lengthto-width ratios were approximately $2.8: 1,2: 1,1.8: 1$ and 2.25:1 in C. picta dorsalis, $T$. scripta elegans, $P$. concinna concinna, and T. carolina triunguis, respectively. Male ratios were 2.2:1, 3:1, 2:1, and 2.3:1, respectively. All kidneys in Emydidae were positioned parallel to the midline and had a slight ventral angle toward the caudal region. The kidneys of T. carolina triunguis appeared smaller than kidneys of other members of the family compared to body size.

For both sexes of all species, the kidneys were connected to the caudal and ventral portion of the lungs via a thin sheet of fascia. This was the only observed cranial anchor point the kidneys possessed. Caudal anchor points were numerous and included fascia connections to the muscles of the pelvic girdle and the vertebral column. In males of all species observed, the kidney was intimate with the reproductive system (Fig. 2c). The testes and epididymides were connected to the kidney via fascia and the ductus deferens passed along the kidney via an invagination and ran parallel to the ureter, eventually emptying into the cloaca. In females, the oviduct passed ventral to the kidney as it connected to the cloaca.

Vascularization of the kidney in all species was similar to the descriptions made by Holtz et al. (1997) regarding $T$. scripta elegans. The aorta projected caudally and the renal arteries diverged from it supplying the kidneys with oxygenated blood. The kidneys were drained by the renal vein which joined the inferior vena cava and returned to the heart (Fig. 4g).

\section{Comparative allometry of turtle kidney and body mass}

Total body mass is influenced by various factors such as gut contents and reproductive status in live animals and mass measurements from preserved specimens may not be as accurate. However, kidney mass is expected to scale with body mass (Braun et al. 2011) and we wished to determine if this could be observed in preserved specimens. Intact kidneys were carefully dissected and each pair was weighed collectively. Kidney mass was plotted against body mass for each species (Figs. 5 and 6). Mass measurements for $C$. serpentina and A. spinifera showed that kidney mass significantly scaled with body mass (Fig. 5a, b; $P=0.024$ and $1.672 \times 10^{-6}$, respectively). This indicated the increase in kidney mass was directly related to an increase in body mass. Members of Kinosternidae, S. odoratus and K. subrubrum, did not show a similar trend between kidney and body 
Fig. 3 Images of adult kidney of Kinosternidae. a, b Dorsal view of Sternotherus odoratus adult female (a) and male (b) kidney. In a, several eggs are observed denoted by e. Scale bar $=10 \mathrm{~mm}$ for both panels $\mathbf{a}$ and $\mathbf{b}$. Fascia covering kidneys in b. c, $\mathbf{d}$ Dorsal view of Kinosternon subrubrum adult female (c) and male (d) kidney. Cranial toward top in all images. $L k$ left kidney, $R k$ right kidney. Muscle denoted with $\mathrm{m}$, intestines denoted with Int. Scale bars $5 \mathrm{~mm}$ in $\mathbf{c}$ and $\mathbf{d}$
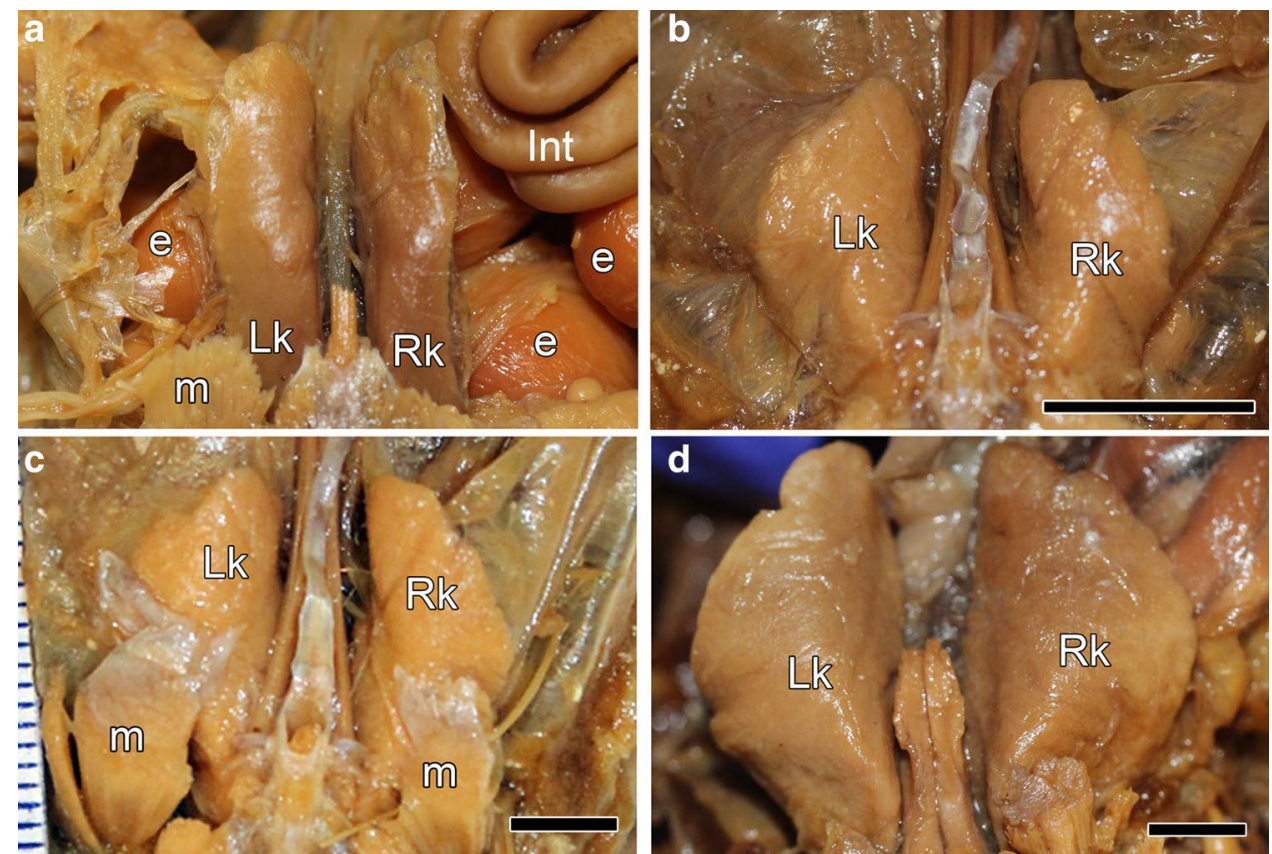

mass. In both kinosternids species, the correlation was not statistically significant, even though the observed trend was a decrease in kidney mass as body mass increased (Fig. 5c, d). However, all other species examined showed an increase in kidney mass with body mass (Figs. 5 and 6).

We examined the kidney and body mass relationship of several species within Emydidae (Fig. 6). Similar to Chelydridae and Trionychidae, the Emydidae family members showed a positive trend of increasing kidney mass with increasing body mass. Chrysemys picta dorsalis, T. scripta elegans, and $P$. concinna concinna all exhibited strong correlations ( $P=0.024,0.017,0.0004$, respectively) between kidney and body mass (Fig. 6a, c, d). The Graptemys geographica (Lesueur, 1817) correlation $P$ value was just greater than 0.05 while $T$. carolina triunguis did not have a significant correlation, although the kidney and body mass relationship trend was similar to other family members (Fig. 6b, e).

\section{Comparative allometry of kidney length and curved carapace length}

The craniocaudal length of left and right kidneys did not vary beyond $0.2 \mathrm{~cm}$ in the species examined. Similar to kidney mass and body mass, average kidney length and CCL were plotted for each species (Figs. 7 and 8). For C. serpentina, kidney length did not show a significant correlation with CCL although the trend observed was increased kidney length with increased CCL (Fig. 7a). On the other hand, there was a significant correlation between kidney length and CCL for A. spinifera (Fig. 7b). A similar trend was observed for $S$. odoratus and K. subrubrum, although resulting in a $P>0.05$, of increasing kidney length with increasing CCL (Fig. 7c, d).

With respect to the Emydidae family members analyzed, three of the five species studied displayed significant correlations between kidney length and CCL. Chrysemys picta dorsalis $\left(P=8.47 \times 10^{-5}\right), T$. scripta elegans $(P=0.003)$, and $P$. concinna concinna $(P=0.008)$ revealed significant correlations suggesting a strong relationship between the length of the kidneys and the curved carapace (Fig. 8a, c, d). Significant correlations for the same three species were also observed for kidney and body mass (Fig. 6). Graptemys geographica and $T$. carolina triunguis did not show significant correlation or a trend similar to other species analyzed between kidney length and CCL (Fig. 8b, e). Based on the specimens of G. geographica and T. carolina triunguis used for this study, kidney length did not change as carapace length increased.

\section{Interspecies comparisons of mass and length data}

Pairwise, interspecies comparisons were also conducted on mass and length data. Using the kidney and body mass measurements for each species, we plotted the kidney mass/ body mass ratios (Fig. 9a). Interspecies comparisons were performed to determine significant differences in kidney mass/body mass ratios (Supplemental Table 1). There were differences between species in observed kidney mass/ body mass ratios such as between $A$. spinifera and $C$. serpentina $(P=0.014)$ or $C$. picta dorsalis and $K$. subrubrum $(P=0.042)$. Significant differences in mass ratios were not 
Fig. 4 Images of adult kidney in Emydidae. a, b Dorsal view of Chrysemys picta dorsalis adult female (a) and male (b) kidney. c, $\mathbf{d}$ Dorsal view of Trachemys scripta elegans adult female (c) and male (d) kidney. Fascia membrane covering kidneys in $\mathbf{c}$ and $\mathbf{d}$. e, f Dorsal view of Pseudemys concinna concinna adult female (e) and male (f) kidney. $\mathbf{g}$, $\mathbf{h}$ Dorsal view of Terrapene carolina triunguis adult female (g) and male (h) kidney. In $\mathbf{g}$, vascular (v) connections can be observed connecting kidneys to vena cava. Cranial toward top in all images. $L k$ left kidney, $R k$ right kidney. Scale bars $5 \mathrm{~mm}$
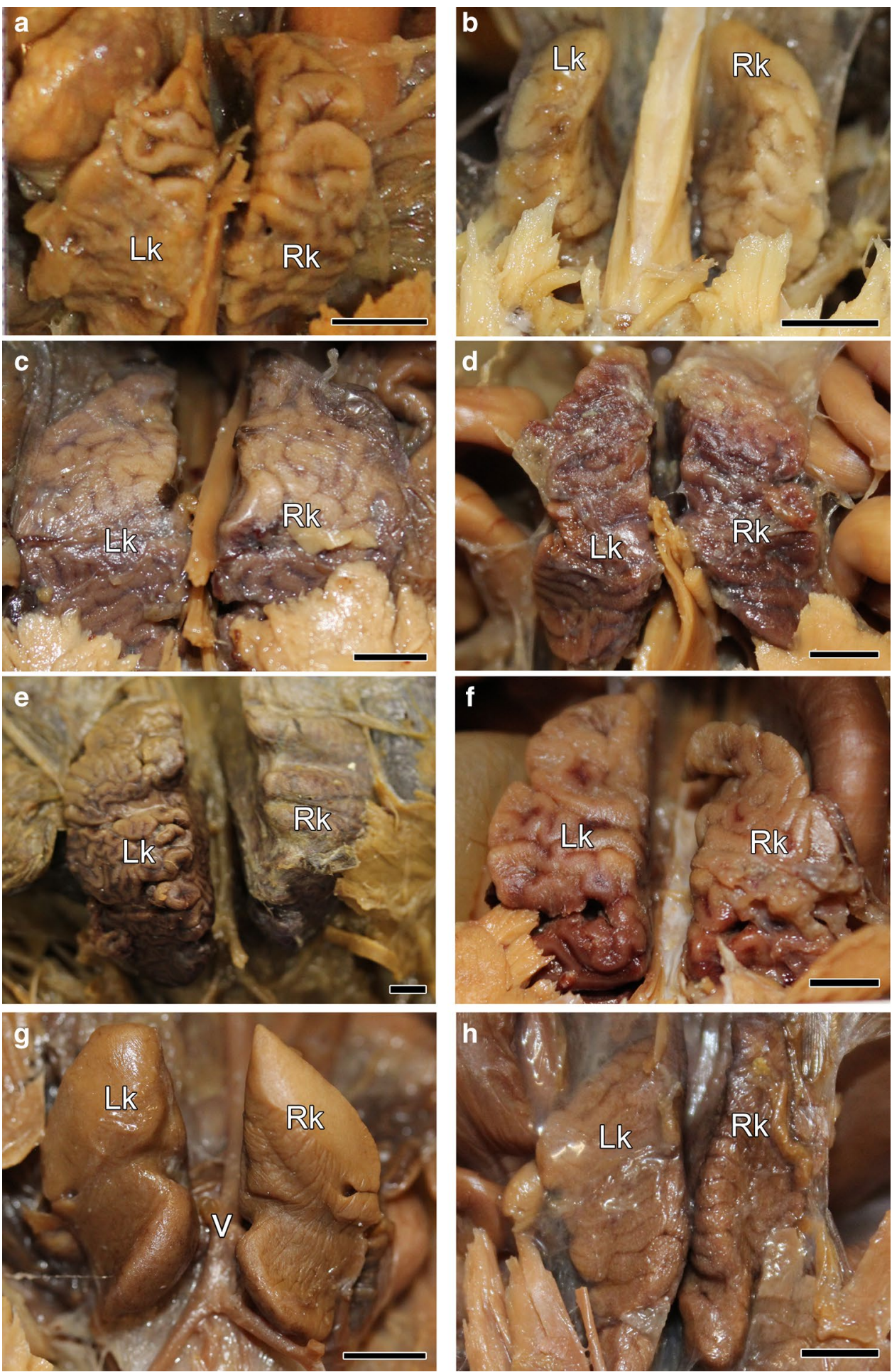

restricted between turtle families but were also observed between species within Emydidae (Supplemental Table 1).

In addition to kidney/body mass ratios, we calculated the percent of body mass that was composed by kidney mass (Supplemental Figure 1). The largest kidney mass percentage of body mass was observed in A. spinifera, $T$. scripta elegans, and $P$. concinna concinna while the smallest percentages were detected in C. serpentina, C. picta dorsalis, and T. carolina triunguis (Supplemental Figure 1). In addition, kidney mass percentage of body mass was determined for each species and interspecies comparisons were conducted. Calculated $P$ values between species is shown in Supplemental Table 2 with those that were $P<0.05$ in bold type. Significant differences were varied among species and 
a

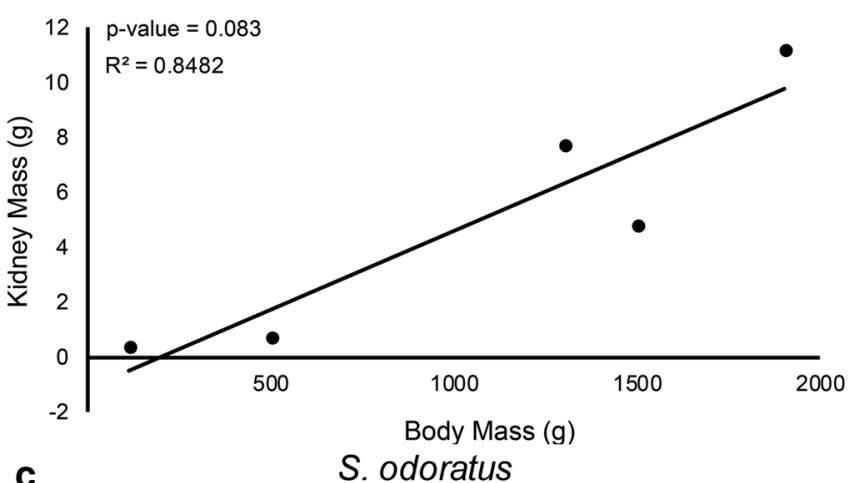

C

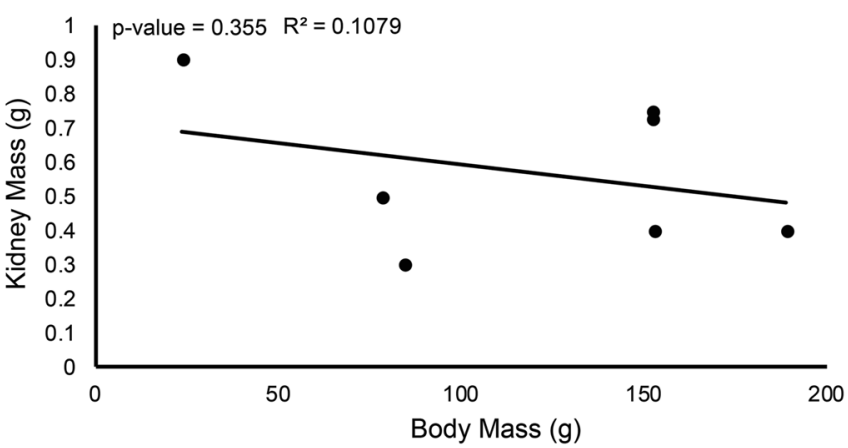

Fig. 5 Linear relationship between kidney and body mass in species from Chelydridae, Trionychidae, and Kinosternidae. a Chelydra serpentina. b Apalone spinifera. c Sternotherus odoratus. d Kinosternon subrubrum. $P$ values determined by Spearman's rank correlation for

families with S. odoratus, $K$. subrubrum, and C. picta dorsalis having the highest number statistically significant differences with other species examined (Supplemental Table 2). Kidney length/CCL ratios for each species were determined (Fig. 9b) and interspecies comparisons are shown in Supplemental Table 3. Several species, when compared, displayed significant differences between kidney length/CCL ratios. Interestingly, the kidney length/CCL ratio for $K$. subrubrum was quite different from all other species examined except for C. serpentina (Fig. 9b, Supplemental Table 3).

\section{Discussion}

\section{Diversity of kidney external morphology}

We set out to extend previous studies on turtle kidney external morphology (Fox 1977; Solomon 1985; Canny 1998; Silva et al. 2010), and provide further detail into turtle kidney anatomy along with relationships between organ size and body size. This was accomplished first by imaging kidneys in situ. From observations and tissue imaging, all species observed in this study contained variable degrees of convolution on the surface of the kidneys. It is possible that b

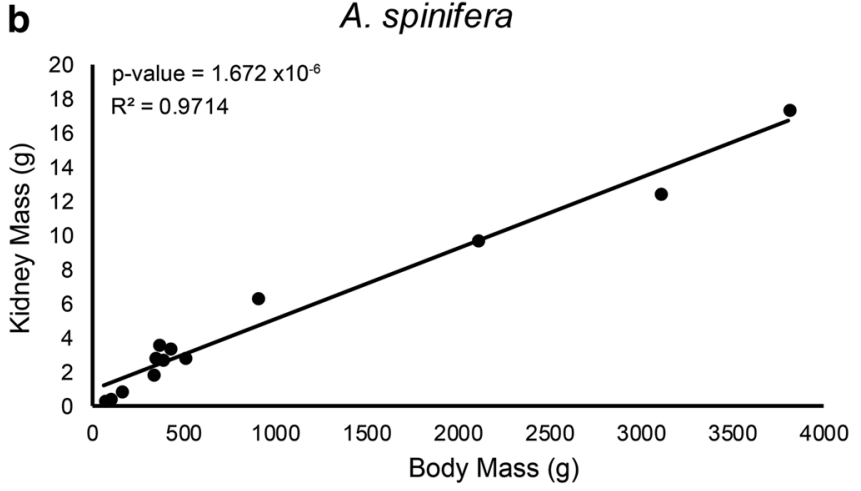

d

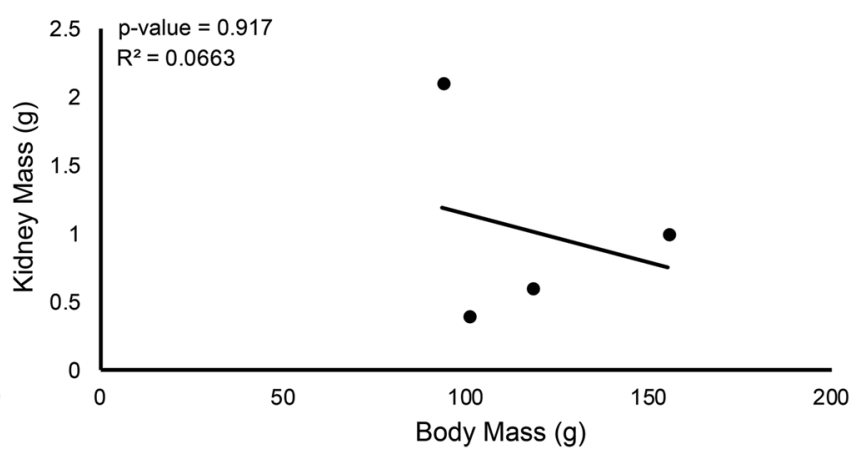

each species. Linear regression slopes for Chelydra serpentina was 1.18 , Apalone spinifera was 0.89 , Sternotherus odoratus was -0.19 , Kinosternon subrubrum was -0.30

tissue preservation may have introduced morphological artifacts in the specimens examined. However, the external morphology we describe for the species studied aligns with previous reports (Fox 1977; Solomon 1985; Silva et al. 2010) and with morphology established during embryogenesis (Camarata, unpubl. data). Additionally, external kidney morphology remained fairly consistent among the families, and the variations observed could be linked to several variables including body morphology, phylogeny, and life histories.

The external kidney morphology of Apalone is likely linked to overall body morphology. Members of this genus are dorsoventrally flattened with a leathery carapace comprised of nine pairs of ribs and 22 dermal plates (Sheil 2003). The flattening of the kidneys may be a result of the flattened body plan. Large, bulky kidneys in the body cavity would take up too much space and could place pressure on other organs in the body cavity. The flattened kidneys have a reduced dorsoventral aspect, but expand both mediolaterally and craniocaudal to compensate for the reduction. This morphology is even more pronounced in females, likely as a result of being gravid. In other turtle species examined in this study, female organs will distend cranially and dorsally as developing eggs fill the body cavity. The body morphology of Apalone only allows for organs to distend cranially 
a

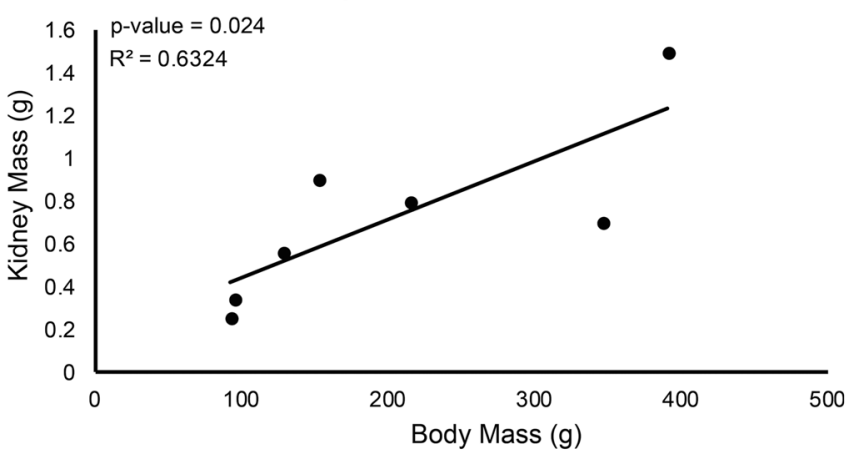

C

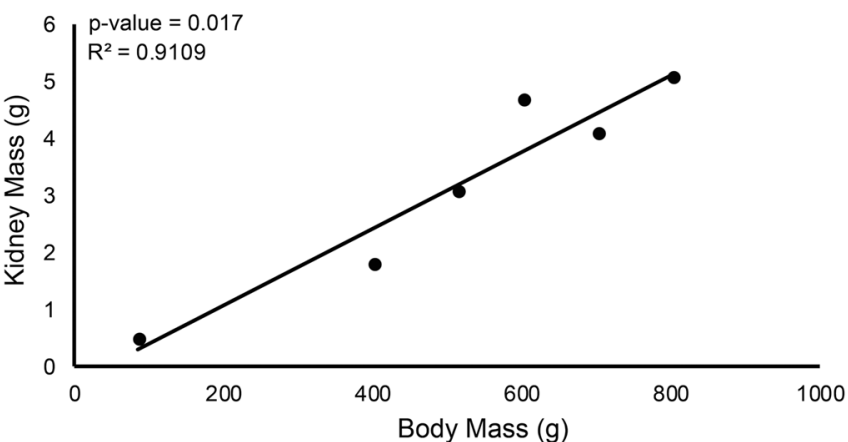

e

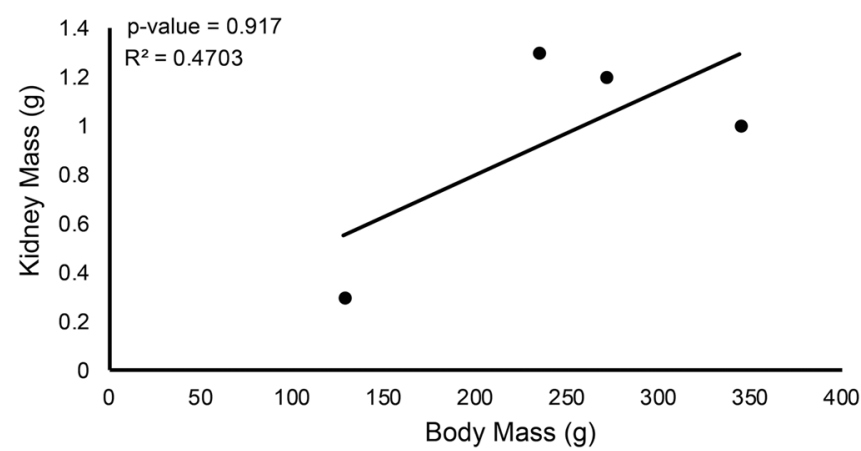

b

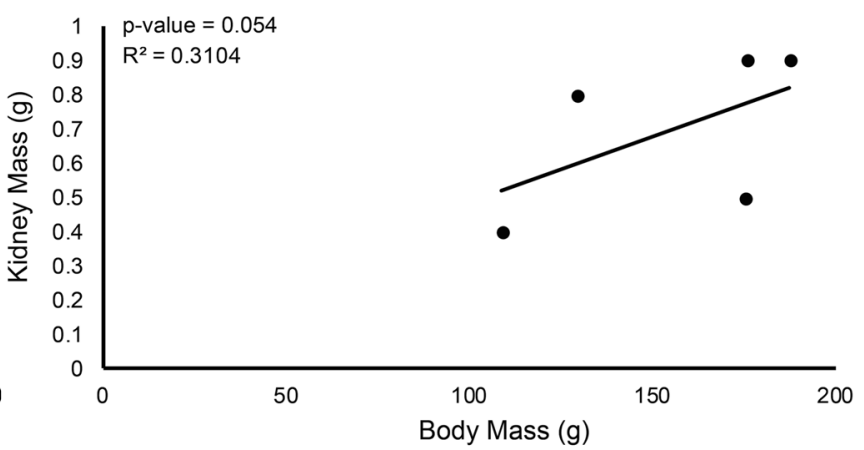

d

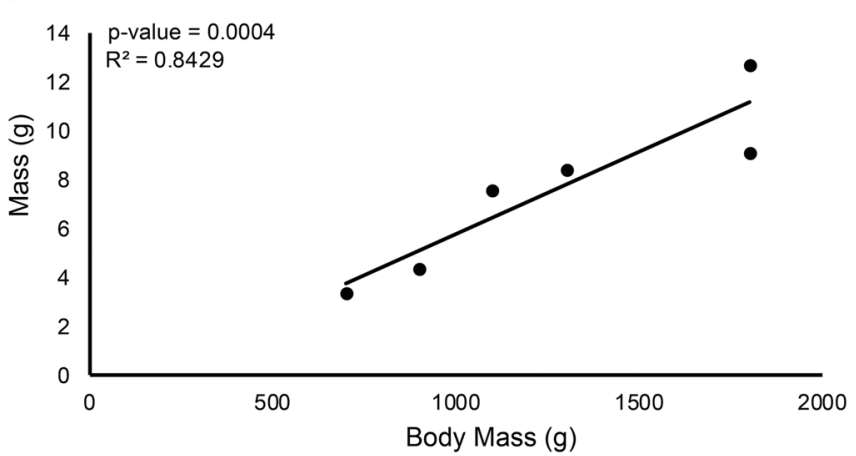

Fig. 6 Linear relationship between kidney and body mass of species in Emydidae. a Chrysemys picta dorsalis. b Graptemys geographica. c Trachemys scripta elegans. d Pseudemys concinna concinna. e Terrapene carolina triunguis. $P$ values determined by Spearman's rank

while the kidneys, being held in a relatively static position, do not distend but flatten to an even further degree. It is still unknown if this kidney modification affects physiology or efficiency.

Members of the family Chelydridae have substantial carapaces intimately connected to the vertebral column and ribs, but possess a cross shaped plastron that minimally protects the venter (Trauth et al. 2004). This morphology allows the turtles to grow quite large, but not necessarily be bound by the typical constraints of other turtles. As they grow, the body tends to push outward around the plastron and carapace and the turtles can add mass and size without being bound by a shell. Interestingly, we found the kidneys of these turtles correlation for each species. Linear regression slopes for Chrysemys picta dorsalis was 0.85 , Graptemys geographica was 0.93, Trachemys scripta elegans was 1.05 , Pseudemys concinna concinna was 1.19 , Terrapene carolina triunguis was 1.39

to be almost embedded within the ribs. The kidneys of Chelydridae even possessed grooves, which we termed renal costal grooves, demarcating where the ribs and vertebral column would lie. The close proximity of the kidney with bony structures in Chelydridae is reminiscent of what has been reported in birds, where the paired kidneys are found recessed into the bony synsacrum (Johnson 1968; Dantzler and Braun 1980).

Members of Kinosternidae are small turtles that possessed a higher domed carapace than turtles from other families examined in this study. The orientation of the kidneys did not vary much from those found in Emydidae, although the external surface of Kinosternidae kidneys did 
a

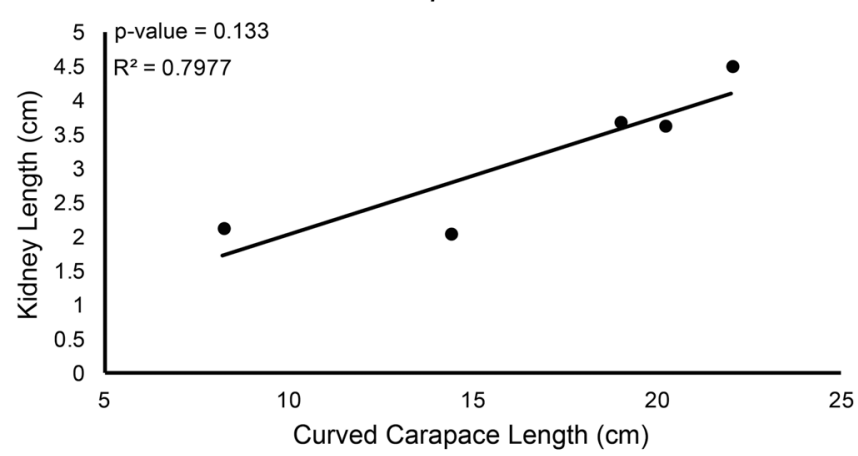

C

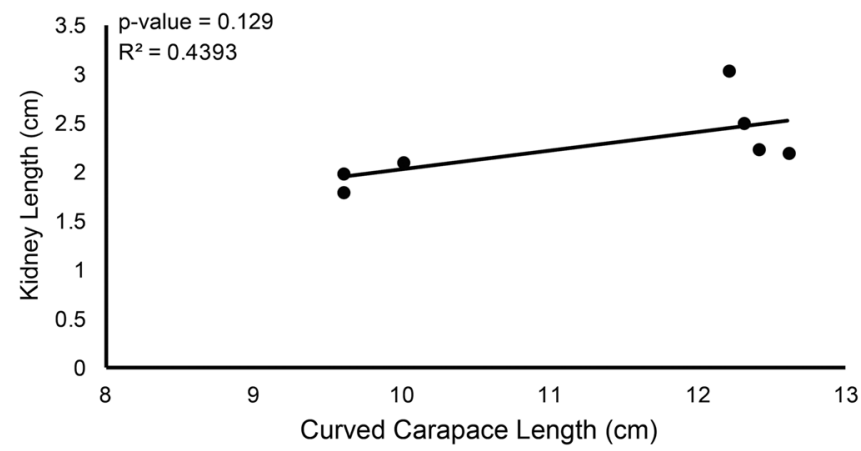

Fig. 7 Linear relationship between curved carapace and kidney length in species from Chelydridae, Trionychidae, and Kinosternidae. a Chelydra serpentina. b Apalone spinifera. c Sternotherus odoratus.

not show significant convolutions. Similar to Trionychidae, females observed in this family had compressed kidneys. However, the kidneys were laterally compressed rather than dorsoventrally compressed. This is likely a result of the shell morphology. With taller body profiles, any distension to organs from maturing eggs could happen in a more dorsal fashion, moving organs further dorsally to accommodate the eggs. This would likely put a strain on breathing for gravid females, but allow for less organ distension overall and could possibly allow for larger clutch sizes. This would also be potentially beneficial if kidney physiology was affected by the change in morphology, by allowing larger and older females to produce more eggs with less strain on the kidneys. As such, we would expect to see clutch sizes and overall health and fitness of females to increase with age and size (Bjorndal and Carr 1989; Hays and Speakman 1991; Rowe 1994).

Members of Emydidae analyzed in this study, typically known as pond turtles, displayed very similar kidney morphology, including distinct convolutions on the surface of the organ. Only Terrapene had a slight deviation from the kidney morphology of the family. In general, their kidneys appeared smaller and less convoluted than other species in the family. Mature females of Emydidae, as in the other families studied, had compressed kidneys, likely a result b
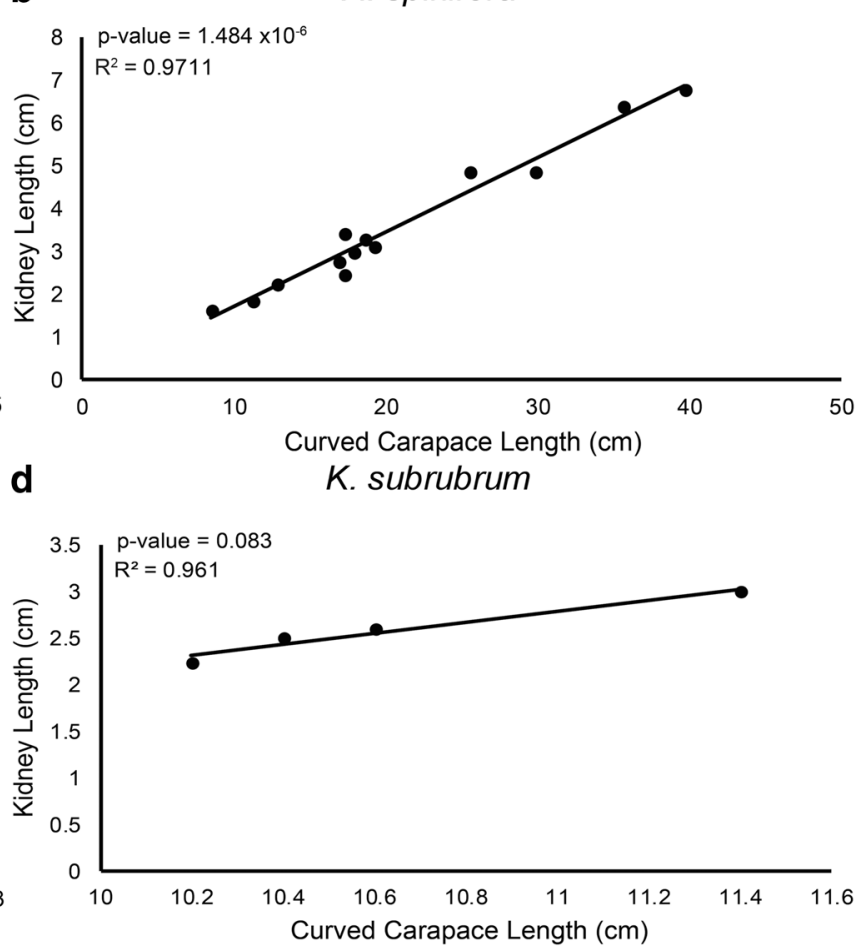

d Kinosternon subrubrum. $P$ values determined by Spearman's rank correlation for each species

from being gravid. Unlike other families, Emydidae possesses terrestrial species. The three-toed box turtle is a terrestrial species that rarely ventures into aquatic habitats. This difference in life history compared to other members of the family can likely be observed in differences in both kidney morphology and physiology. The connection between species ecology, body plan such as carapace size, and renal morphology is unknown.

Kidneys of aquatic species tend to be focused on maintaining electrolyte balance as opposed to the kidneys of terrestrial species which tend to be focused on maintaining water balance (Kardong 2012). It is still unknown if the renal physiologies of these species differ. However, external kidney morphology appears to be highly variable between species and families, and it is likely that internal kidney morphology could also vary. It has been reported that the lobed reptile kidney has a specific organization with renal corpuscles lining the center of each lobe and the collecting ducts positioned at right angles to the long axis of the kidney (Braun et al. 2011). This organization has been found in the American alligator (Alligator mississippiensis), however, such tissue organization has not detected thus far in other reptiles (Moore et al. 2009; Camarata et al. 2016). Future studies will be aimed to correlate external morphology with histological organization 
a

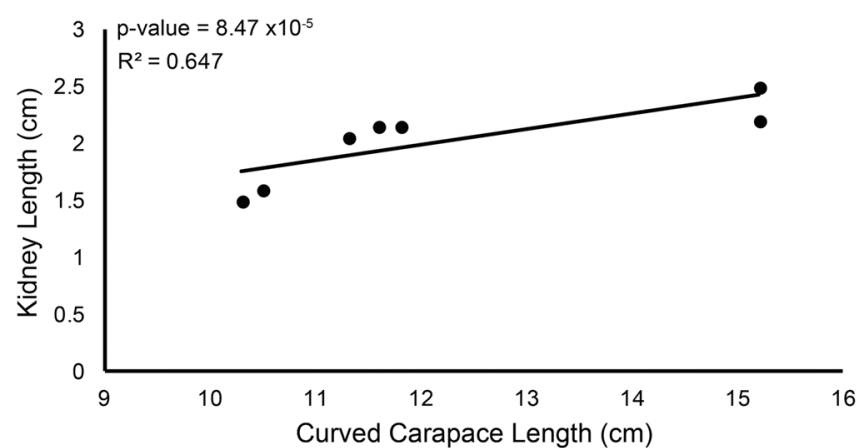

C

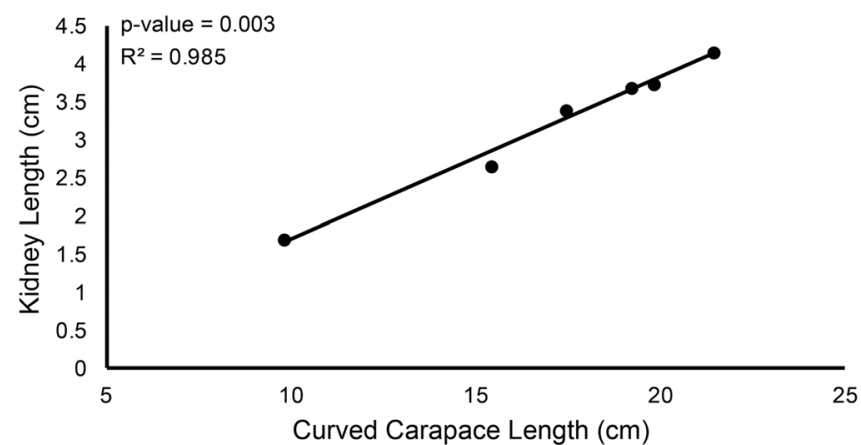

e

T. carolina triunguis

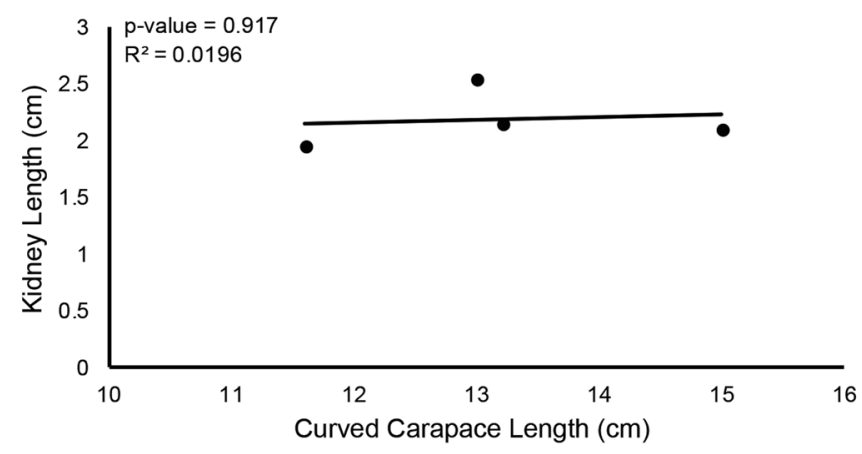

Fig. 8 Linear relationship between curved carapace and kidney length in species from Emydidae. a Chrysemys picta dorsalis. b Graptemys geographica. c Trachemys scripta elegans. d Pseudemys concinna

of tissue, which is expected to be established during embryogenesis.

\section{Comparative kidney allometry}

Kidney length and CCL tended to scale together. That is, as CCL length increased so did kidney length. Two exceptions to the trend were G. geographica and T. carolina where the slope between kidney length and CCL was close to zero. However, both species did display increased kidney mass along with body mass, suggesting kidney growth was not craniocaudal. As described above, the patterns in organ growth are most likely influenced by physical constraints of carapace size/shape or development of eggs in females along b

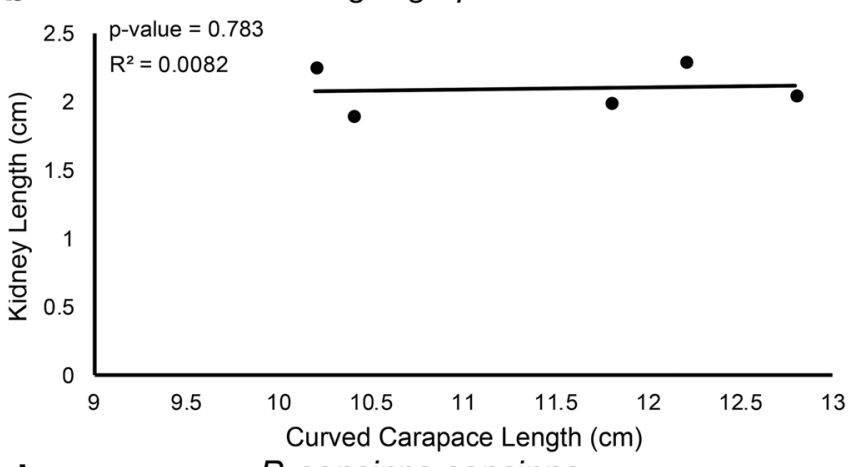

d

P. concinna concinna

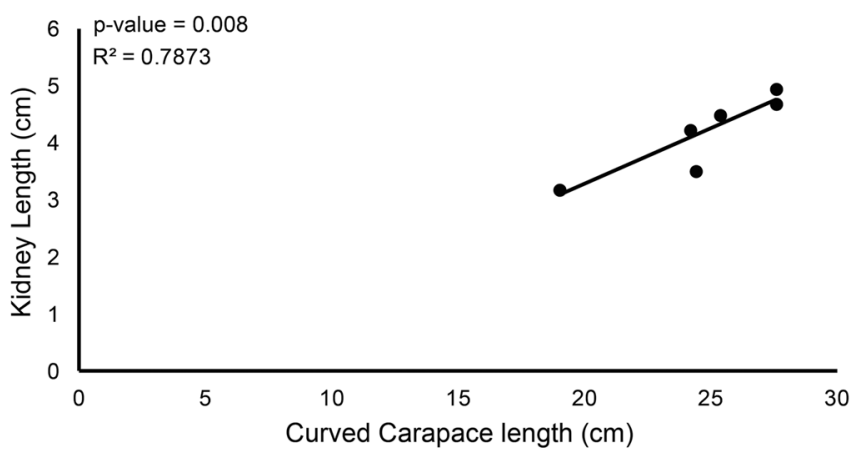

concinna. e Terrapene carolina triunguis. $P$ values determined by Spearman's rank correlation for each species

with physiological requirements. We also determined the percentage of body mass that is composed of kidney mass. The observations of the turtle species examined in this study show most turtle species with approximately $0.5 \%$ kidney mass of body mass, a value closer to that found in mammals (0.5\%) than that found in birds (1\%; Braun et al. 2011).

In mammals, one of the biggest determinants driving kidney shape and organization is body mass (Braun et al. 2011). The ratio between kidney mass and body mass should reflect organ physiology. As body size increases so does fluid volume and therefore renal function. As a result, kidney mass should scale with increasing body mass. In general, organ scaling with body mass has been expressed using the formula $Y=a M^{b}$ (Adolph 1949). $Y$ is 
Fig. 9 Species comparisons of body and kidney measurements. a Boxplot of body mass to kidney mass ratios. b Boxplot of curved carapace length-tokidney length ratios. Boxplot data displayed as median (dark black line), interquartile range (box-25th-75th quartile), minimum and maximum values (bars), and suspected outliers (open circles). Pairwise comparison data is displayed in Supplemental Tables 1-3. CHSE, C. serpentina; APSP, A. spinifera; STOD, S. odoratus; KISU, K. subrubrum; CHDO, C. picta dorsalis; GRGE, G. geographica; TRSC, T. scripta elegans; PSCO, P. concinna concinna; TECA, T. carolina triunguis

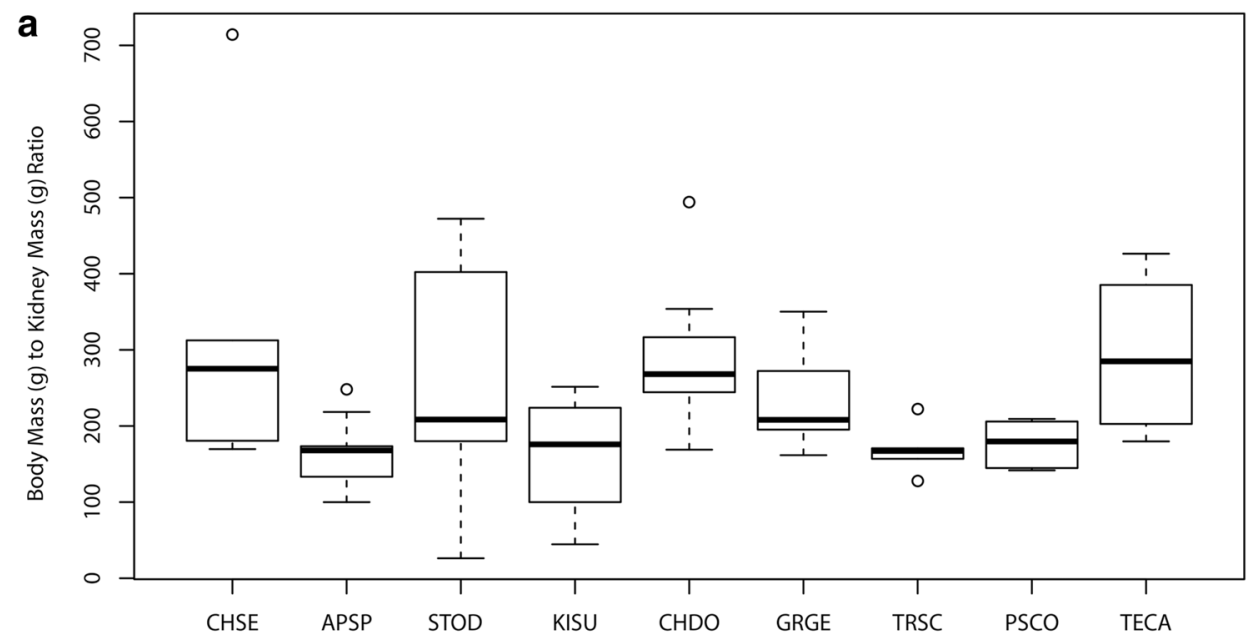

b

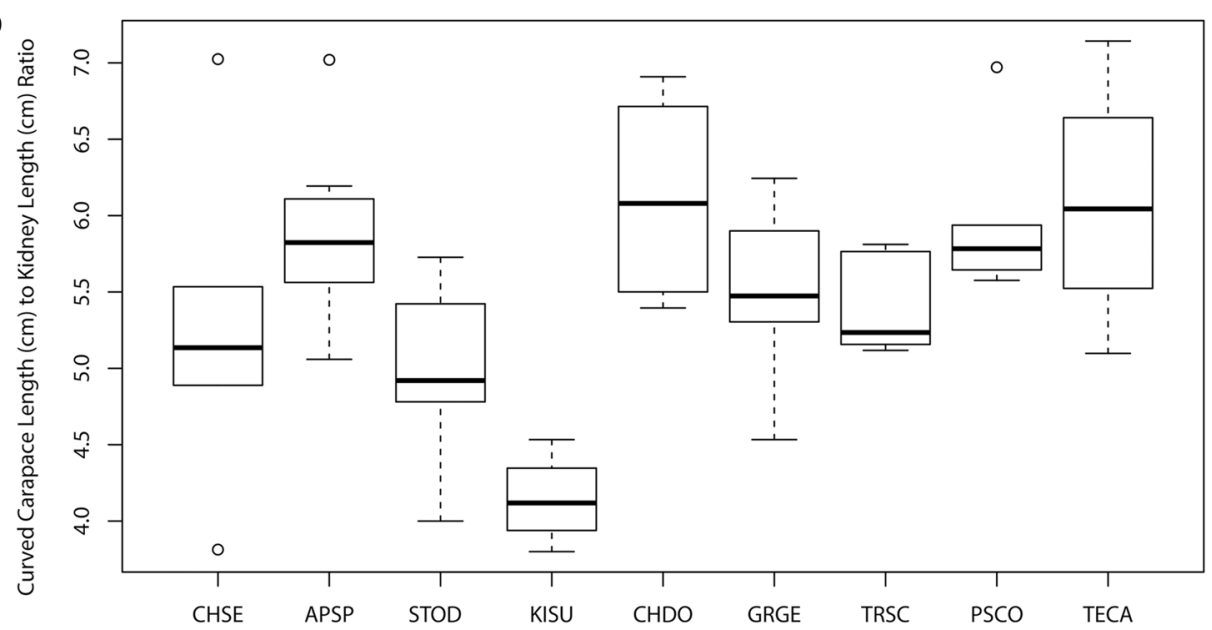

a dependent function of body mass, $M$, and $b$ is the slope of the regression line where $a$, is the intercept of $Y$ when $M=1$ (Lindstedt and Schaeffer 2002). The empirical term, $b$, acts as a scaling factor for the tissue under study in relation to body mass. For mammals, the scaling factor for kidney to body mass has been calculated to be 0.85 (Calder and Braun 1983). Generalized values for $b$, have been determined for bird and reptile kidney, 0.91 and 0.945 , respectively (Franz et al. 2009). Calculated values of $b$ from our examined specimens produces values between 0.85 (C. picta dorsalis) and 1.39 (T. carolina) (see legends for Figs. 5 and 6). Our data suggests some degree of variation in scaling of kidney mass with body mass in turtles. Although the data collected was from preserved turtles, the calculated scaling factors were still within ranges for previously published values from live animals (Franz et al. 2009). Body mass can be influenced by a number of factors in live animals and seasonal body mass changes has been reported for some reptile species (Rostal et al. 1994; Toledo et al. 2008). However, in Tegu lizards, the scaling factor between body mass and metabolic rate remained constant regardless of season (Toledo et al. 2008). Additionally, kidney morphology in House Sparrows did not change due to seasonal effects (Casotti 2001). As kidney function is directly related to cardiac output and metabolism, it should be expected to scale with body mass at a fairly constant rate regardless of environmental changes such as season or temperature. Allometry of preserved animals can still yield useful information and it will be of interest to directly compare kidney and body mass ratios between preserved and live animals.

Acknowledgements We would like to thank the Arkansas Center for Biodiversity Collections for specimen access and Dr. Stan Trauth for critical comments on the manuscript.

\section{Compliance with ethical standards}

Conflict of interest All authors declare they have no conflict of interest.

Human and animal rights This article does not contain any studies with human participants or live animals performed by any of the authors. All 
specimens were obtained from the Arkansas Center for Biodiversity Museum Collections at Arkansas State University in adherence with University and State guidelines.

Open Access This article is distributed under the terms of the Creative Commons Attribution 4.0 International License (http://creativeco mmons.org/licenses/by/4.0/), which permits unrestricted use, distribution, and reproduction in any medium, provided you give appropriate credit to the original author(s) and the source, provide a link to the Creative Commons license, and indicate if changes were made.

\section{References}

Adolph EF (1949) Quantitative relations in the physiological constitutions of mammals. Science 109:579-585. https://doi.org/10.1126/ science.109.2841.579

Bjorndal KA, Carr A (1989) Variation in clutch size and egg size in the Green Turtle nesting population at Tortuguero, Costa Rica. Herpetologica 45:181-189

Bolton AB (1999) Techniques for measuring sea turtles. In: Eckert KAB, Abreu Grobois FA, Donnelly M (eds) Management and research techniques for the conservation of sea turtles. IUCN, Gland, pp 110-114

Braun EJ (1998) Comparative renal function in reptiles, birds, and mammals. Sem Avian Exot Pet Med 7:62-71

Braun EJ, Dantzler WH (2011) Vertebrate renal system. Compr Physiol, supplement 30: handbook of physiology, comparative physiology. First published in print 1997, pp 481-576. https://doi. org/10.1002/cphy.cp130108

Calder WA, Braun EJ (1983) Scaling of osmotic regulation in mammals and birds. Am J Physiol 244:R601-R606

Camarata T, Howard A, Elsey RM, Raza S, O'Connor A, Beatty B, Conrad J, Solounias N, Chow P, Mukta S, Vasilyev A (2016) Postembryonic nephrogenesis and persistence of Six2-expressing nephron progenitor cells in the reptilian kidney. PLoS One 11:e0153422

Canny C (1998) Gross anatomy and imaging of the avian and reptilian urinary system. Semin Avian Exot Pet Med 7:72-80

Casotti G (2001) Effects of season on kidney morphology in House Sparrows. J Exp Biol 204:1201-1206

Dantzler WH, Braun EJ (1980) Comparative nephron function in reptiles, birds, and mammals. Am J Physiol 239:R197-R213

Fox H (1977) The urogenital system of reptiles. In: Gans C, Parsons TS (eds) Biology of reptilia. Academic Press, London and New York, pp 1-157
Franz R, Hummel J, Kienzle E, Kolle P, Gunga HC, Clauss M (2009) Allometry of visceral organs in living amniotes and its implications for sauropod dinosaurs. Proc R Soc B 276:1731-1736

Hays GC, Speakman JR (1991) Reproductive investment and optimum clutch size of Loggerhead Sea Turtles (Caretta caretta). Br Ecol Soc 60:455-462

Holtz P, Barker IA, Crawshaw GJ, Dobson H (1997) The anatomy and perfusion of the renal portal system in the Red-eared Slider. J Zoo Wildl Med 28:378-385

Johnson OW (1968) Some morphological features of avian kidneys. Auk 85:216-228

Kardong KV (2012) Vertebrates: comparative anatomy, function, evolution, 6th edn. McGraw-Hill, New York, p 794

Lindstedt SL, Schaeffer PJ (2002) Use of allometry in predicting anatomical and physiological parameters of mammals. Lab Anim 36:1-19

Moore BC, Hyndman KA, Cox A, Lawler A, Mathavan K, Guillette LJ (2009) Morphology and histochemistry of juvenile American Alligator (Alligator mississippiensis) nephrons. Anat Rec (Hoboken) 292:1670-1676

Rostal D, Lance V, Grumbles J, Alberts A (1994) Seasonal reproductive cycle of the Desert Tortoise (Gopherus agassizii) in the Eastern Mojave Desert. Herpetol Monogr 8:72-82

Rowe JW (1994) Reproductive variation and the egg size-clutch size trade-off within and among populations of Painted Turtles (Chrysemys picta bellii). Oecologia 99:35-44

Sheil CA (2003) Osteology and skeletal development of Apalone spinifera (Reptilia: Testudines: Trionychidae). J Morphol 256:42-78

Silva GFN, Matos WCG, Freire VTO, Pereira Neto J, Seyfert CE, Faria MD (2010) Dimensions, mass and volume of the turtles kidneys (Trachemys scripta elegans WIED, 1839). J Morphol Sci 27:142-147

Solomon SE (1985) The morphology of the kidney of the Green Turtle (Chelonia mydas L.). J Anat 140(Pt 3):355-369

Toledo LF, Brito SP, Milsom WK, Abe AS, Andrade DV (2008) Effects of season, temperature, and body mass on the standard metabolic rate of Tegu Lizards (Tupinambis merianae). Physiol Biochem Zool 81:158-164

Trauth SE, Robison HW, Plummer MV (2004) Amphibians and reptiles of Arkansas. University of Arkansas Press, Fayetteville, p 421

Publisher's Note Springer Nature remains neutral with regard to jurisdictional claims in published maps and institutional affiliations. 